\title{
RESTRIÇÃO ALIMENTAR E ATIVIDADE OVARIANA LUTEAL CÍCLICA PÓS-PARTO EM VACAS GIROLANDA ${ }^{1}$
}

\author{
ADEMIR DE MORAES FERREIRA², JOÃO HENRIQUE MOREIRA VIANA ${ }^{3}$, WANDERLEI FERREIRA DE SÁ ${ }^{2}$, \\ LUIZ SÉRGIO DE ALMEIDA CAMARGO² e RUI DA SILVA VERNEQUE ${ }^{4}$
}

\begin{abstract}
RESUMO - Objetivou-se neste trabalho verificar se a restrição alimentar no pós-parto em vacas Girolanda, multíparas, de bom escore de condição corporal $(\mathrm{ECC}=3,5$ a 4,5$)$ ao parto será suficiente para impedir o reinício da atividade ovariana luteal cíclica (AOLC) pós-parto. Os animais foram distribuídos em três tratamentos: Grupo I $(n=15)$, mantença; Grupo II $(n=10)$ e Grupo III $(n=13)$, sendo que os grupos II e III receberam restrição alimentar até 90 e 180 dias pós-parto, respectivamente. As pesagens e avaliações do ECC foram efetuadas logo após o parto, e depois semanalmente. A AOLC foi avaliada por palpação retal, observação de cio e concentração de progesterona no leite. Os intervalos do parto ao primeiro cio foram de 53,1,63,2 e 51,2 dias (P>0,05), respectivamente para os Grupos I, II e III, que apresentaram perdas de peso de 7,3 kg, 57,0 kg e 63,7 kg nesse período; e de 14,2 kg, 63,8 kg e 78,4 kg do parto até 90 dias pós-parto, repectivamente. Em vacas Girolanda de bom escore de condição corporal ao parto, a perda de $15,2 \%$ do peso nos três primeiros meses de lactação, e de 16,3\% do peso até 180 dias pós-parto, não é suficiente para atrasar o reinício ou interromper a AOLC nos respectivos períodos.
\end{abstract}

Termos para indexação: condição corporal, ciclo estral, bovinos, subnutrição.

\section{LOW LEVEL OF NUTRITION AND OVARIAN LUTEAL CYCLIC ACTIVITY POSTPARTUM IN CROSSBRED (HOLSTEIN X ZEBU) COWS}

\begin{abstract}
The objective of this study was to evaluate the effect of weight loss on postpartum cross bred Holstein x Gir (HZ) cows in good body score condition $(\mathrm{BSC}=3.5$ to 4.5$)$ at calving on the delay of beginning or on maintenance of ovarian luteal cyclic activity (OLCA). Cows were distributed in three treatments: Group I $(n=15)$, maintenance; Group II $(n=10)$ and Group III $(n=13)$; Groups II and III were feed restricted until 90 and 180 days postpartum, respectively. The weight and BSC were measured after calving and then weekly. The OLCA was evaluated by rectal palpation, estrous detection and milk progesterone level. Intervals from the calving to first estrous were 53.1, 63.2 and 51.2 days (P > 0.05), respectively, for the Groups I, II and III; weight loss were of $7.3 \mathrm{~kg} ; 57.0 \mathrm{~kg}$ and $63.7 \mathrm{~kg}$ up to the first estrous, and of $14.2 \mathrm{~kg}, 63.8 \mathrm{~kg}$ and $78.4 \mathrm{~kg}$ up to 90 days postpartum, for the Groups I, II, and III, respectively. In cross bred (HZ) cows in good body score condition at calving, the weight loss of $15.2 \%$ of body weight in the first three months of milking, and of $16.3 \%$ up to 180 days postpartum do not arrest the beginning or impair the maintenance of OLCA.
\end{abstract}

Index terms: body condition, estrous cycle, bovines, malnutrition.

\footnotetext{
${ }^{1}$ Aceito para publicação em 8 de fevereiro de 2000 . Parcialmente financiado pelo CNPq e pela FAPEMIG.

${ }^{2}$ Méd. Vet., Embrapa-Centro Nacional de Pesquisa de Gado de Leite (CNPGL), Rua Eugênio do Nascimento, 610, Dom Bosco, CEP 36038-330 Juiz de Fora, MG. E-mail: ademirmf@cnpgl.embrapa.br, wandefsa@cnpgl.embrapa.br, camargo@cnpgl.embrapa.br ${ }^{3}$ Méd. Vet., Embrapa-CNPGL. Bolsista do CNPq.

E-mail: jhmviana@cnpgl.embrapa.br

${ }^{4}$ Zootec., Embrapa-CNPGL.

E-mail: rsverneque@cnpgl.embrapa.br
}

\section{INTRODUÇÃO}

A maximização da exploração de gado leiteiro tem como base a eficiência reprodutiva, cujo fator mais limitante, no Brasil, é o manejo nutricional. A insuficiente ingestão de nutrientes, via dieta inadequada, é causa comum de infertilidade ao atrasar a puberdade e prolongar o anestro após o parto, por bloqueio da atividade ovariana (Ferreira, 1993). A maior ou menor influência da nutrição sobre a re- 
produção está na dependência de fatores como intensidade e duração da restrição alimentar, escore da condição corporal (ECC), idade e estado fisiológico.

Em virtude do longo intervalo de partos no rebanho leiteiro nacional (Carneiro, 1992), o Brasil está deixando de produzir cerca de 10 bilhões de litros anualmente (Ferreira, 1991a) que, somados aos 20 bilhões produzidos, alcançariam os 30 bilhões de litros de leite/ano, citados como demanda para o ano 2000 (Gomes, 1996). Objetivando alcançar a meta desejável de um intervalo de partos próximo de 12 meses, torna-se necessário que a vaca manifeste o estro e conceba até 90 dias pós-parto (Ferreira, 1991a; Ferguson, 1996).

No Brasil, a maioria dos rebanhos é caracterizada por apresentar um nível nutricional inadequado, mesmo os menos exigentes do ponto de vista genético, fazendo com que a inatividade ovariana pós-parto (anestro) constitua-se na principal causa do longo intervalo de partos. A alta taxa de animais em anestro foi confirmada por Ferreira et al. (1992), que encontraram, em 3.408 vacas de 50 rebanhos leiteiros da Zona da Mata de Minas Gerais, 73,1\% de vacas em anestro até 90 dias pós-parto e 54,4\% após esse período. A inatividade ovariana estava quase sempre associada ao baixo ECC.

Vários autores enfatizam a importância do ECC ao parto para o rápido reinício da atividade ovariana luteal cíclica (AOLC) pós-parto (Selk et al., 1988; VillaGodoy et al., 1988; Richards et al., 1989; Bakke, 1993; Harris Junior, 1993), enquanto outros afirmam que o ECC bom ao parto permite uma certa perda de peso no início da lactação sem atrasar o aparecimento do estro pós-parto (Yoshimeki et al., 1986; Boyd et al., 1987; Garnsworthy \& Jones, 1987; Villa-Godoy et al., 1988; Ferguson, 1996).

Segundo Ferreira (1995), as principais causas do anestro prolongado pós-parto são o baixo ECC ao parto e a excessiva perda de peso nos dois a três primeiros meses da lactação em animais com ECC regular ou bom ao parto. Desta forma, ECC bom ao parto e mantença ou perda de pouco peso até dois a três meses pós-parto são condições indispensáveis para o rápido reinício da AOLC no pós-parto. A literatura é carente em informações sobre a relação nutrição e reaparecimento de cios pós-parto em vacas mestiças HZ, havendo necessidade de mais estudos a respeito, visto que já foram observadas diferenças na fisiologia reprodutiva (duração e intensidade do cio, tamanho do folículo ovulatório e corpos lúteos, etc.), no padrão de deposição de gordura (mais interna ou externamente) influenciando a avaliação da condição corporal e outras, entre zebuínos e taurinos (Ferguson \& Otto, 1989; Barros et al., 1995, 1998). Essa necessidade se acentua quando se trata de animais mestiços.

O escore da condição corporal, valor numérico atribuído à variação da condição corporal, ao parto, influencia alguns parâmetros reprodutivos, pois, como observaram Ruegg et al. (1992), vacas da raça Holandesa com menor escore da condição corporal ao parto apresentaram maior intervalo do parto ao primeiro estro. Dessa maneira, o ECC tem sido proposto como método auxiliar no manejo nutricional e reprodutivo de rebanhos leiteiros (Hady et al., 1994).

Os objetivos do presente trabalho foram verificar se a restrição alimentar no período da seca (pastejo em Brachiaria decumbens, sem suplementação volumosa ou concentrada) no pós-parto, em vacas Girolanda de bom ECC ao parto e produção conhecida de lactações anteriores variando de 7,0 a 13,0 kg leite/dia, será capaz de impedir o reinício da AOLC até 90 dias pós-parto ou cessar a AOLC até 180 dias pós-parto.

\section{MATERIAL E MÉTODOS}

O trabalho foi conduzido na Fazenda Experimental de Santa Mônica, localizada no Município de Valença, RJ, e pertencente à Embrapa-Centro Nacional de Pesquisa de Gado de Leite (CNPGL). Utilizaram-se 38 vacas Girolanda, com diferentes graus de sangue, com peso médio de $479,7 \pm 59,4 \mathrm{~kg}$ e escore da condição corporal (ECC) bom ao parto, ou seja, entre 3,5 a 4,5 pontos, na escala de 1 (muito magra) a 5 (gorda) descrita por Ferreira (1991a), e produção média de $10,2 \mathrm{~kg}$ de leite/dia no primeiro mês de lactação. Quinze vacas receberam alimentação pósparto calculada para atender às necessidades de mantença e produção, e constituíram o Grupo I, enquanto 23 vacas foram submetidas à restrição alimentar durante a lactação (1 UA/ha, em pasto de Brachiaria decumbens, no período da seca, sem qualquer suplementação), das quais 10 tiveram o estro observado até 90 dias (Grupo II) e 13 até 180 dias pós-parto (Grupo III). Os estros observados foram anotados. 
A produção média diária aos 15 dias pós-parto foi de $10,9,10,5$ e $9,8 \mathrm{~kg}$ de leite dos Grupos I, II e III, respectivamente. Os animais do Grupo I receberam suplementação de $3 \mathrm{~kg}$ de concentrado/dia até o 15ㅇ dia pós-parto, a partir do qual passaram a receber o concentrado de acordo com a produção $(1 \mathrm{~kg}$ para cada três litros de leite acima de $8 \mathrm{~kg}$ de leite/dia), além de cana e uréia entre as ordenhas, e pastagem no restante do período. $\mathrm{O}$ cálculo das necessidades de mantença do grupo teve como base a média de peso vivo dos animais. Como a alimentação foi padronizada nos Grupos II e III sob restrição alimentar (apenas pastejo), e a produção dos animais variou de 7,0 a 12,5 kg de leite/dia (Grupo II) e 6,8 a 12,7 kg de leite/dia (Grupo III), é de se esperar que os animais apresentem diferentes porcentuais de perda de peso pós-parto.

Os animais foram pesados e tiveram a condição corporal avaliada e ECC determinado 24 horas após o parto, e depois semanalmente, sempre após a ordenha da manhã e antes do oferecimento de alimentos ou água. Promoveramse duas ordenhas diárias, e o leite foi pesado 10 dias após o parto e depois a cada sete dias. A atividade ovariana luteal cíclica (AOLC) foi avaliada como segue: a) palpação retal semanal a partir do 15ำ dia pós-parto; b) observação do estro duas vezes ao dia (manhã e tarde); e c) níveis de progesterona no leite (amostra semanal). As dosagens de progesterona foram realizadas pelo método do radioimunoensaio (RIA), segundo a técnica de Dobson \& Fitzpatrick (1976) modificada, no Laboratório de Radioimunoensaio da Embrapa-CNPGL. Considerou-se como atividade luteal os níveis de progesterona no leite $>3,0 \mathrm{ng} / \mathrm{mL}$. A modificação introduzida na técnica desses autores constou da extração da fração gordurosa do leite com éter.

A variável intervalo do parto ao primeiro estro (IPPC), em dias, e as variações de peso (perda e peso) até o primeiro estro e 30,60, 90 ou 180 dias pós-parto foram avaliadas por análise de variância usando-se o procedimento GLM do SAS (SAS Institute, 1993) e admitindo-se um modelo linear que inclui o efeito de grupo e erro. Para avaliação da variável IPPC, foi também proposto um modelo similar ao anterior, incluindo-se, como covariável em efeito linear, a variação de peso (perda de peso) de cada vaca, verificada até 30 dias pós-parto, para avaliar se vacas de maior oscilação de peso nos primeiros 30 dias pós-parto apresentavam comportamento diferenciado em termos de IPPC. As comparações múltiplas entre médias de tratamentos nas características analisadas foram realizadas usando-se o teste $\mathrm{t}$ de Student a $5 \%$ de probabilidade.

\section{RESULTADOS E DISCUSSÃO}

Observou-se que $100 \%, 100 \%$ e $92,3 \%$ dos animais dos Grupos I, II e III, respectivamente, apre- sentaram cio até 90 dias pós-parto. Não foi observado efeito do grupo $(\mathrm{P}>0,05)$ sobre o número de dias até a ocorrência do $1^{\circ}$ cio (Grupo I $=53,1 ; \mathrm{II}=63,2 \mathrm{e}$ $\mathrm{III}=51,2$ dias $)$, conforme mostrado na Tabela 1 , mas observou-se nesse período maior perda de peso $(\mathrm{P}<0,05)$ entre os animais dos Grupos II e III em relação ao Grupo I. As perdas de peso do parto até 90 dias pós-parto foram diferentes entre os Grupos I, II e III $(\mathrm{P}<0,05)$.

$\mathrm{O}$ fato de os animais do grupo controle terem apresentado um peso e comportamento ponderal heterogêneo (variação de +14 a $-43 \mathrm{~kg}$ ) até 90 dias pósparto parece sugerir que as necessidades de mantença não foram atendidas para alguns animais desse grupo, cuja produção variou de 8,4 a 14,8 kg/dia. Isso provavelmente ocorreu pelo fato de as necessidades de mantença terem sido calculadas para a média de peso vivo do grupo.

O anestro prolongado pós-parto representa o principal problema reprodutivo na pecuária leiteira nacional (Ferreira et al., 1992). Vacas com reserva corporal ao parto fisiologicamente são capazes de resistir à condição de subnutrição, mobilizando parte da gordura corporal nos primeiros meses de lactação para produção de leite, sem sacrificar a AOLC (Moore \& Rocha, 1983), ou seja, não atrasando o aparecimento do primeiro estro pós-parto, desde que essa perda de peso não seja excessiva (Boyd et al., 1987; Garnsworthy \& Jones, 1987). Essas afirmações podem explicar o precoce reaparecimento do estro pósparto (menos de 65 dias),obtido no presente trabalho, em vacas mestiças com ECC bom ao parto e sob restrição alimentar no início da lactação.

As perdas de peso verificadas do parto ao primeiro estro (em torno de $12,0 \%$ ) e até 90 dias pós-parto (máximo de 15,2\% no Grupo III), o que corresponde às perdas, respectivamente, de 0,902 e 1,244 kg/dia, não foram suficientes para impedir o aparecimento do estro até três meses pós-parto, enquanto a perda média de $16,3 \%$ do peso até 180 dias $(0,468 \mathrm{~kg} / \mathrm{dia})$ não provocou cessação da AOLC nesse período. O bovino cessa a AOLC quando perde de $20 \%$ a $24 \%$ de seu peso corporal (Ferguson, 1996), taxa de perda de peso superior à verificada no presente trabalho, $\mathrm{o}$ que pode explicar a não-interrupção da AOLC nos animais estudados. 
TABELA 1. Efeito da restrição alimentar em vacas mestiças Holandês $x$ Zebu de condição corporal boa ao parto, sobre o intervalo parto-primeiro estro, variação do peso vivo e do escore da condição corporal (médias e desvio-padrão) ${ }^{1}$.

\begin{tabular}{|c|c|c|c|}
\hline \multirow[t]{2}{*}{ Itens $^{2}$} & \multirow{2}{*}{$\begin{array}{l}\text { Controle } \\
\text { (Grupo I) }\end{array}$} & \multicolumn{2}{|c|}{ Restrição alimentar } \\
\hline & & Grupo $\mathrm{II}^{3}$ & ${\text { Grupo } \mathrm{III}^{4}}^{4}$ \\
\hline $\begin{array}{l}\text { Intervalo do parto ao primeiro estro (dias) } \\
\text { Valores mínimos e máximos observados (dias) }\end{array}$ & $\begin{array}{l}53,1 \pm 19,7 \mathrm{a} \\
(23 \text { e } 84)\end{array}$ & $\begin{array}{l}63,2 \pm 16,7 \mathrm{a} \\
(38 \text { e } 90)\end{array}$ & $\begin{array}{l}51,2 \pm 26,7 \mathrm{a} \\
(23 \mathrm{e} 92)\end{array}$ \\
\hline \multicolumn{4}{|l|}{ Peso vivo dos animais $(\mathrm{kg})$} \\
\hline Parto & $452,3 \pm 52,8$ & $470,1 \pm 28,9$ & $518,7 \pm 65,8$ \\
\hline 30 dias pós-parto $(\mathrm{kg})$ & $447,4 \pm 45,9$ & $427,7 \pm 26,7$ & $465,0 \pm 65,2$ \\
\hline PPRP (kg) & $5,6 \pm 13,3 a$ & $42,4 \pm 10,0 b$ & $53,7 \pm 15,0 \mathrm{c}$ \\
\hline PPRP $(\%)$ & $2,3 \pm 1,7 \mathrm{a}$ & $9,0 \pm 2,0 b$ & $10,4 \pm 2,9 c$ \\
\hline PPMD (kg) & 0,187 & 1,413 & 1,790 \\
\hline 60 dias pós-parto $(\mathrm{kg})$ & $445,0 \pm 45,4$ & $418,2 \pm 25,2$ & $450,8 \pm 64,6$ \\
\hline PPRP (kg) & $6,6 \pm 16,2 a$ & $51,9 \pm 11,7 b$ & $67,8 \pm 13,9 c$ \\
\hline PPRP $(\%)$ & $2,9 \pm 2,2$ & $11,0 \pm 2,2$ & $13,2 \pm 2,6$ \\
\hline PPMD (kg) & 0,110 & 0,865 & 1,130 \\
\hline 90 dias pós-parto $(\mathrm{kg})$ & $438,1 \pm 46,5$ & $406,3 \pm 29,0$ & $440,3 \pm 64,1$ \\
\hline PPRP (kg) & $14,2 \pm 17,1 \mathrm{a}$ & $63,8 \pm 11,9 b$ & $78,4 \pm 14,2 \mathrm{c}$ \\
\hline (valores extremos) & $(14 a-43)$ & $(-48 a-85)$ & $(-58 a-110)$ \\
\hline PPRP $(\%)$ & $3,8 \pm 2,8$ & $13,6 \pm 2,5$ & $15,2 \pm 2,0$ \\
\hline (valores extremos) & $(0,2$ a 10,3$)$ & $(10,4$ a 18,7$)$ & $(9,7$ a 19,6$)$ \\
\hline PPMD (kg) & 0,158 & 0,709 & 0,871 \\
\hline 180 dias pós-parto $(\mathrm{kg})$ & - & - & $435,4 \pm 57,8$ \\
\hline $\begin{array}{l}\text { PPRP (kg) } \\
\quad \text { (valores extremos) }\end{array}$ & - & - & $\begin{array}{l}84,2 \pm 16,0 \\
(-60 a-122)\end{array}$ \\
\hline $\begin{array}{l}\operatorname{PPRP}(\%) \\
\quad \text { (valores extremos) }\end{array}$ & - & - & $\begin{array}{c}16,3 \pm 2,4 \\
(12,4 \text { a } 20,7)\end{array}$ \\
\hline PPMD (kg) & - & - & 0,463 \\
\hline $1^{0}$ estro pós-parto $(\mathrm{kg})$ & $445,0 \pm 46,1$ & $412,1 \pm 30,7$ & $455,6 \pm 70,1$ \\
\hline $\begin{array}{l}\text { PPRP (kg) } \\
\text { (valores extremos) }\end{array}$ & $\begin{array}{l}7,3 \pm 14,7 a \\
(15 a-35)\end{array}$ & $\begin{array}{l}57,0 \pm 12,1 b \\
(-42 a-75)\end{array}$ & $\begin{array}{c}63,7 \pm 13,4 c \\
(-37 a-81)\end{array}$ \\
\hline $\operatorname{PPRP}(\%)$ & $2,9 \pm 1,9$ & $12,1 \pm 2,5$ & $12,2 \pm 3,6$ \\
\hline (valores extremos) & $(0,5$ a 7,2$)$ & $(8,5$ a 16,5$)$ & $(5,9$ a 17,7$)$ \\
\hline PPMD (kg) & 0,137 & 0,902 & 1,244 \\
\hline \multicolumn{4}{|l|}{ Escore da condição corporal } \\
\hline Parto & $3,8 \pm 0,2$ & $3,8 \pm 0,2$ & $4,1 \pm 0,4$ \\
\hline $1^{\circ}$ estro pós-parto & $3,6 \pm 0,2$ & $3,1 \pm 0,2$ & $3,3 \pm 0,5$ \\
\hline 90 dias pós-parto & $3,5 \pm 0,3$ & $2,9 \pm 0,2$ & $3,1 \pm 0,4$ \\
\hline 180 dias pós-parto & - & - & $3,0 \pm 0,3$ \\
\hline Cios não identificados (\%) & 30,0 & 38,1 & 36,1 \\
\hline
\end{tabular}

A literatura é escassa em trabalhos semelhantes com vacas Girolanda, tendo-se conhecimento apenas do trabalho de Assis (1995), que observou intervalos do parto ao primeiro cio de 70 dias em vacas em pasto de Brachiaria decumbens e de 67 dias em vacas suplementadas com $1 \mathrm{~kg}$ de fubá e $20 \mathrm{~kg}$ de cana com uréia/dia. Assim como no presente trabalho, os animais apresentaram cio antes do período desejado, de 90 dias pós-parto. 
Vários autores citam que a perda de $10 \%$ a $15 \%$ do peso corporal no início da lactação não afeta o reinício da AOLC em animais puros de grande porte e boa condição corporal ao parto (Nicol, 1977; Hansen et al., 1982; Yoshimeki et al., 1986; Boyd et al., 1987; Garnsworth \& Jones, 1987; Ferguson, 1996), assim como Villa-Godoy et al. (1988) afirmam que a perda de $106 \mathrm{~kg}$ ou 17,6\% do peso ao parto, no início da lactação, não foi suficiente para afetar a reprodução de vacas Holandesas de $601 \mathrm{~kg}$, alta produção e bom estado nutricional ao parto. Esses resultados estão de acordo com os observados no presente trabalho, em que a restrição alimentar oferecida nos primeiros três meses pós-parto, embora acarretasse perdas de $15,2 \%$ do peso ao parto, não influenciou o intervalo do parto ao primeiro estro $(\mathrm{P}>0,05) \mathrm{em}$ vacas Girolanda de ECC bom ao parto, pois a média desse intervalo nos dois grupos sob restrição alimentar foi menor que 65 dias, não sendo diferente do grupo que recebeu alimentação adequada. Acreditase que vacas de maior produtividade nas mesmas condições de subnutrição apresentariam maior taxa de perda de peso no período estudado de 90 a 180 dias pós-parto, o que poderia acarretar cessação da AOLC, fato não observado neste trabalho em vacas com média de 10,2 $\mathrm{kg}$ de leite/dia no primeiro mês de lactação.

A ingestão de dietas energéticas insuficientes para atender a produção de leite ou mantença, resulta em balanço energético negativo (BEN). Segundo Butler \& Canfield (1989), o BEN atrasa o reinício da AOLC pós-parto, processo no qual podem estar envolvidos insulina, glicose, ácidos graxos livres e $\mathrm{IGF}_{1}$. A influência do BEN no aparecimento do estro pósparto não foi observada no presente trabalho, visto que nas vacas sob restrição alimentar e perdendo peso (Grupos II e III), o IPPC não diferiu daquelas que receberam alimentação adequada no início da lactação (Grupo I), o que concorda com Ferguson (1996), ao afirmar que a AOLC pós-parto reinicia independentemente de o animal estar em BEN ou balanço energético positivo (BEP), desde que apresente reserva corporal, que ao ser mobilizada forneça energia suficiente para atender à produção de leite $\mathrm{e}$ função luteal cíclica ovariana. Da mesma forma, Spicer et al. (1990) não verificaram diferença no IPPC entre vacas com BEM e BEP.
As elevadas perdas de peso/dia verificadas até 30 dias pós-parto, nos Grupos II e III, não foram suficientes para impedir o crescimento folicular e o aparecimento do estro nos 30 dias seguintes (Tabela 1), provavelmente causado pela energia proveniente das reservas corporais mobilizadas. Entretanto, outros estudos se fazem necessários para verificar a fertilidade nesses cios, visto haver citações de que os folículos que crescem com o animal em condições de BEN apresentam qualidade inferior (Britt, 1992, 1994), reduzindo a taxa de concepção, o que não foi avaliado no presente trabalho.

No Grupo III verificou-se que a perda média de peso vivo até 90 e 180 dias pós-parto não foi suficiente para cessar a AOLC (Tabela 1), visto que nesse grupo, os animais apresentaram estros durante o período estudado de seis meses. Esses resultados de perdas de peso sem cessar a AOLC confirmam a importância das reservas corporais para a manifestação precoce do $1^{\circ}$ estro pós-parto, embora se deva enfatizar novamente a necessidade de se estudar a fertilidade dos cios manifestados em vacas Girolanda quando em BEN.

Nos animais sob restrição alimentar (Grupos II e III) os escores da condição corporal sofreram reduções ao primeiro estro e aos 90 dias pós-parto (Tabela 1). Dessa maneira, era de se esperar que esses animais continuassem apresentando AOLC, visto que a cessação da AOLC ocorre tão somente quando as fêmeas bovinas atingem ECC $\leq 2,2$ (Richards et al., 1989; Ferreira, 1990; Short et al., 1990), o que não ocorreu no presente trabalho.

O escore da condição corporal desejável no momento da secagem da vaca é próximo de 3,5 , enquanto no momento do parto é de 3,5 a 4,0 (Ferreira, 1991a; Harris Junior, 1991a, 1991b). Recomenda-se que o ECC de vacas leiteiras seja avaliado nos diferentes estádios da lactação, pois essa vigilância é importante para se evitar que algumas vacas cheguem à secagem muito magras, e não haja tempo de recuperar as reservas necessárias durante o período em que estiverem secas, para que cheguem ao parto com boa condição corporal (Ferreira, 1995; Saun \& Sniffen, 1996) e assim evitando-se o anestro pósparto, conforme mostrado no presente experimento.

Verificaram-se $30 \%, 38,1 \%$ e $36,1 \%$ de cios provavelmente não identificados (Tabela 1) entre os 
Grupos I, II e III, respectivamente, com base nos níveis de progesterona elevados, sem registro de cios. Esses índices estão abaixo dos 47,3\% e 50\% de cios não identificados verificados por Ferreira (1991b) em rebanhos da Zona da Mata, MG, e por Sprecher et al. (1995) na Universidade de Michigan, USA, respectivamente. As taxas obtidas eram esperadas, por se saber que apenas dois períodos de observação não são suficientes para a identificação de todos os cios, além de que no pós-parto há ocorrência de ciclos mais curtos, cios de menor intensidade e ovulações sem sinais externos de cio.

O presente trabalho mostra quão importante é o bom ECC da vaca para o rápido retorno da AOLC pós-parto, um dos fatores de maior importância para uma boa eficiência reprodutiva. Entretanto, chamase atenção para o fato de que condições corporais extremas por ocasião do parto podem provocar prejuízos fisiológicos ao animal e econômicos ao produtor. Desta maneira, vacas com condição corporal inferior (magras) ao parto têm a ovulação inibida e maior período de anestro pós-parto (Fox, 1991), alongando o intervalo de partos, com conseqüente redução na produção e produtividade (Ferreira, 1991a), enquanto vacas gordas ao parto, principalmente aquelas de alta produção reduzem o consumo de alimentos (menor produção), aumentam o risco de aparecimento da cetose e apresentam menor taxa de concepção. Além disso, o alimento convertido no excesso de gordura poderia estar sendo utilizado por outra vaca para produzir leite (Ferreira, 1991b).

\section{CONCLUSÕES}

1. Em vacas Girolanda, multíparas, com escore de condição corporal bom ao parto, a perda de até $15,2 \%$ e $16,3 \%$ do peso vivo do parto a 90 e 180 dias pósparto, respectivamente, não impede o reinício da atividade ovariana luteal cíclica.

2. A perda média de até 1,0 unidade do escore de condição corporal do parto a 90 dias pós-parto, em vacas parindo com boa condição corporal $(\mathrm{ECC}=4)$, não afeta o reinício da atividade ovariana luteal cíclica pós-parto em vacas Girolanda.

\section{REFERÊNCIAS}

ASSIS, E. de J. Efeito da suplementação alimentar pósparto, na época seca do ano, sobre a produção e reprodução de vacas mestiças holandês $x$ zebu, de boa condição corporal. Seropédica : UFRRJ, 1995. 50p. Dissertação de Mestrado.

BAKKE, M. Rotina das vacas define manejo. Balde Branco, São Paulo, n.349, p.9-11, 1993.

BARROS, C.M.; FIGUEIREDO, R.A.; PINHEIRO, O.L. Estro, ovulação e dinâmica folicular em zebuínos. Revista Brasileira de Reprodução Animal, Belo Horizonte, v.19, n.1/2, p.9-22, 1995.

BARROS, C.M.; MOREIRA, M.B.P.; FERNANDES, P. Pharmacological manipulation of the estrous cycle to improve artificial insemination or embryo transfer programs. Arquivo da Faculdade de Veterinária da UFRGS, Porto Alegre, v.26, n.1, p.179-198, 1998.

BOYD, G.W.; KISER, T.E.; COWREY, R.S. Effects of pre-partum energy intake on steroid during late gestation on cow and calf performance. Journal of Animal Science, Champaign, v.64, n.6, p.17031709, 1987.

BRITT, J.H. Here's the theory on why early breeding works. Hoard's Dairyman, Atkinson, v.139, n.14, p.599, 1994.

BRITT, J.H. Nutrition, weight loss affect reproduction, embryonic death. Feedstuffs, Minnetonka, v.64, n.21, p.12-13, 17, 1992.

BUTLER, W.R.; CANFIELD, R.W. Interrelationships between energy balance and postpartum reproduction. In: CORNELL NUTRITION CONFERENCE FOR FEED MANUFACTURERS, 1989, Ithaca. Proceedings. Ithaca : Cornell University, 1989. p.66-74.

CARNEIRO, J.M. Principais problemas da bovinocultura de leite: o caso de Minas Gerais. Belo Horizonte : Fundação João Pinheiro, 1992. 219p.

DOBSON, H.; FITZPATRICK, R.J. Clinical applications of the progesterone in milk test. British Veterinary Journal, London, v.132, n.5, p.538-542, 1976.

FERGUSON, J.D. Diet, production and reproduction in dairy cows. Animal Feed Science and Technology, Amsterdam, v.59, p.173-184, 1996. 
FERGUSON, J.D.; OTTO, K.A. Managing body correlation in dairy cows. In: CORNELL NUTRITION CONFERENCE FOR FEED MANUFACTURERS, 1989, Ithaca. Proceedings. Ithaca : Cornell University, 1989. p.75-87.

FERREIRA, A. de M. Efeito da amamentação e do nível nutricional na atividade ovariana de vacas mestiças leiteiras. Viçosa : UFV, 1990. 132p. Tese de Doutorado.

FERREIRA, A. de M. Manejo reprodutivo e eficiência da atividade leiteira. Coronel Pacheco : EmbrapaCNPGL, 1991a. 47p. (Embrapa-CNPGL. Documentos, 46).

FERREIRA, A. de M. Novos conceitos sobre o anestro pós-parto. In: CONGRESSO BRASILEIRO DE REPRODUÇÃO ANIMAL, 11., 1995, Belo Horizonte. Anais. Belo Horizonte : Colégio Brasileiro de Reprodução Animal, 1995. p.62-70.

FERREIRA, A. de M. Nutrição e atividade ovariana em bovinos. Pesquisa Agropecuária Brasileira, Brasília, v.28, n.9, p.1077-1093, set. 1993.

FERREIRA, A. de M. Redução do período de serviço em taurinos. In: CONGRESSO BRASILEIRO DE REPRODUÇÃO ANIMAL, 9., 1991, Belo Horizonte. Anais. Belo Horizonte : Colégio Brasileiro de Reprodução Animal, 1991b. p.22-32.

FERREIRA, A. de M.; SÁ, W.F.; VILLAÇA, H. de A.; ASSIS, A.G. de. Diagnóstico da situação produtiva e reprodutiva em rebanhos leiteiros da Zona da Mata, MG. Pesquisa Agropecuária Brasileira, Brasília, v.27, n.1, p.91-104, jan. 1992.

FOX, D.G. Predicting body condition score changes in cows from calculated energy balance. In: NUTRITION CONFERENCE FOR FEED MANUFACTURERS, 1991, Ithaca. Proceedings. Ithaca : Cornell University, 1991. p.52-56.

GARNSWORTHY, P.C.; JONES, G.P. The influence of body condition at calving and dietary protein supply and voluntary food intake and performance in cows. Animal Production, Edinburgh, v.44, n.3, p.347353, 1987.

GOMES, S.T. A economia do leite. Coronel Pacheco Embrapa-CNPGL, 1996. 104p.

HADY, P.J.; DOMECO, J.J.; KANEENE, J.B. Frequency and precision of body condition scoring in dairy cattle. Journal of Dairy Science, Champaign, v.77, n.6, p.1543-1547, 1994.
HANSEN, P.J.; BAIK，D.H.; RUTLEDGE，J.J.; HAUSER, E.R. Genotype $\mathrm{x}$ environmental interactions on reproductive traits of bovine females. I. Post-partum reproduction as influenced by genotype, dietary regimen, level of milk production and parity. Journal of Animal Science, Champaign, v.55, n.6, p.1458-1472, 1982.

HARRIS JUNIOR, B. Dry cow feeding and management. Gainesville : University of Florida, 1991a. 8p. (Circular, 623)

HARRIS JUNIOR, B. Feeding for maximum milk production and reproductive performance. Gainesville : University of Florida, 1991b. 8p. (Circular, 915)

HARRIS JUNIOR, B. Feeding for maximum reproductive performance. Agropractice, Gainesville, v.14, n.3, p.39-41, 1993.

MOORE, P.C.; ROCHA, C.M.C. da. Reproductive performance of gyr cows: the effect of weaning age of calves and postpartum energy intake. Journal of Animal Science, Champaign, v.57, n.4, p.807-814, 1983.

NICOL, A.M. The influence of plane of nutrition immediately post-calving on the performance of beef cows. New Zealand Society of Animal Production Proceedings, Hamilton, v.37, p.103-108, 1977.

RICHARDS, M.W.; WETTEMAN, R.P.; SCHOENEMANN, H.M. Nutritional anestrus in beef cows: body weight change, body condition, luteinizing hormone in serum and ovarian activity. Journal of Animal Science, Champaign, v.67, n.6, p.1520-1526, 1989.

RUEGG, P.L.; GOODGER, W.J.; HOLMBERG, C.A.; WEAVER, L.D.; HOFMAN, E.M. Relation among body condition score, serum urea nitrogen and cholesterol concentrations, and reproductive performance in high-producing Holstein dairy cows in early lactation. American Journal of Veterinary Research, Schaumburg, v.53, n.1, p.10-14, 1992.

SAS INSTITUTE (Cary, Estados Unidos). SAS/STAT software: syntax, version 6. Cary, 1993. 151p.

SAUN, R.J. van; SNIFFEN, C.J. Nutritional management of the pregnant dairy cow to optimize health, lactation and reproductive performance. Animal Feed Science and Technology, Amsterdam, v.59, p.1326, 1996. 
SELK, G.E.; WETTEMANN, R.P.; LUSBY, K.S.; OLTJEN, J.W.; MOBLEY, S.L.; RASBY, R.T.; GARMENDIA, J.C. Relationships among weight change, body condition, ovarian activity and estrus behaviour. Journal of Animal Science, Champaign, v.66, n.12, p.3153-3159, 1988.

SHORT, R.E.; BELLOWS, R.A.; STAGMILLER, R.B.; BERARDINELLI, J.G.; CUSTER, E.E. Physiological mechanisms controlling anestrus and infertility in post-partum beef cows. Journal of Animal Science, Champaign, v.68, n.3, p.799-816, 1990.

SPICER, L.J.; TUCKER, W.B.; ADAMS, J.D. Insulinlike growth factor-I in dairy cows: relationships among energy balance, body condition, ovarian activity and estrus behaviour. Journal of Dairy Science, Champaign, v.73, n.4, p.929-937, 1990.
SPRECHER, D.J.; FARMER, J.A.; NEBEL, R.L.; MATHER, E.C. The education implications of reproductive problems identified during investigations at Michigan dairy farmers. Theriogenology, New York, v. 43, n.1, p.373-380, 1995.

VILLA-GODOY, A.; HUGHES, T.L.; EMERY, R.S.; CHAPIN, C.T.; FOGWELL, R.L. Association between energy balance and luteal function in lactating dairy cows. Journal of Dairy Science, Champaign, v.71, n.4, p.1063-1072, 1988.

YOSHIMEKI, S.; NAKAO, T.; MORYOCHI, N.; KAWATA, K. Effect of energy and protein intake on ovarian activity in postpartum high-producing Holstein cows. Japanese Journal of Zootechnical Science, Tokyo, v.57, n.7, p.553-560, 1986. 